\title{
Effect of a Corpus-based Grammar Teaching Method in the Chinese EFL Environment
}

\author{
Xin Wang, 2 \\ ${ }^{1}$ Graduate School, Xi'an International Studies University \\ ${ }^{2}$ School of Foreign Languages, Henan University \\ ${ }^{1}$ Xi'an, China \\ 2 Kaifeng, China \\ bakerwangwang@163.com
}

\begin{abstract}
The present study se ts out to explore the effect of corpus-based grammar teaching method in the EFL context. Participants were 40 Chinese undergraduate EFL learners who were assigned to the experimental and control class through random sampling and then were taught with the corpus-based teaching method and the traditional teaching method respectively. The two classes kept conformity as regards the teacher, the grammar coursebook and the period distribution. Pre-test showed that there was no statistically significant difference between the two classes. After a one-term teaching experiment, however, post-test revealed a higher grammatical proficiency of the experimental class. Besides, interviews and class observations also demonstrated that students in the experimental class underwent change in their ideology of grammar. They endorsed the corpus-based teaching method and took a positive attitude towards it at large. Pedagogical implications of these findings, limitations of this study and suggestions for the future research are discussed.
\end{abstract}

Keywords-corpus-based; grammar teaching; Chinese EFL classroom; effect

\section{INTRODUCTION}

Numerous research finding have demonstrated the significant role grammar teaching plays in EFL learning. However, in spite of many approaches put forward to promote effective and efficient grammar teaching, survey shows that in the grammar teaching classroom, the traditional teaching method, also called the grammar-translation method still remains popular [1]. The traditional teaching method is characterized by the emphasis on accuracy of forms and rule learning [2], to the neglect of meanings and contextual environment. That is why the traditional method can't arouse the enthusiasm of students and its effect is not satisfactory. As a matter of fact, grammar is not a static system of rules but a dynamic system of authentic use. As what is pointed out by Larsen-Freeman [1], "grammar not only has to do with form and meaning, but also with use in texts..." A corpus is a collection of spoken and written materials stored in an electronic database [3]. The materials in corpora are authentic

This paper was financially supported by the 15th Education Research Fund of Henan University: "the Corpus-based English Grammar Teaching" (HDXJJG2015-108) and Xi'an International Studies University Research Fund for Graduate Students: "A Study of the Interface between metaphor and metonymy" (syjsb201710). We are deeply indebted to their support. examples used in specific contexts. Corpus- based method is an approach of using corpora "as a source of quantitative evidence", which is different from corpus-driven method that is a form of "basic evidence for linguistic categories" [4]. Compared with corpus-driven method, corpus-based method is "guided and controlled corpus search", so it is more effective for learners at various levels [5]. Therefore, it is decided that corpus-based rather than corpus-driven teaching method is to be applied to grammar instruction in the present research.

\section{REVIEW OF LITERATURE}

A review of literature shows that much has been discussed about grammar instruction, including the significant role grammar teaching play in language learning, and the approaches of grammar teaching [1] [5-6]. A variety of approaches have been proposed, among which corpus-based approach is one that has received a lot of attention. To the best of our knowledge, research of the corpus-based method to grammar teaching is mainly concerned with three aspects: the necessity and applicability of corpus-based approach to grammar [7-9], application of corpus to grammar instruction in specific fields [10], empirical studies of corpus-based grammar teaching [4-5]. However, though there is extensive study of corpus-based grammar teaching, the majority of them are only theoretical discussion. To date, due to various reasons, there are few empirical studies, not to mention empirical studies with Chinese EFL students as research participants, a gap, it is hoped that can be partially filled by the present study.

\section{Features of Corpus-BAsed Grammar TeAching METHOD}

Compared with the traditional teaching method, the corpusbased English Grammar teaching has the following characteristics:

\section{A. Autonomous learning of students}

Different from the traditional teaching method which is replete with isolated explanations and decontextualized exercises, corpus-based method is a meaningful, integrative method. By dint of this method, students are invited to find the specific use of grammatical expressions themselves under the guidance of the teacher. Therefore, corpus-based English 
grammar teaching method contributes to fostering the students' exploratory learning ability.

\section{B. Authentic materials}

The traditional grammar teaching method often resorts to fabricated examples which may be grammatically correct but semantically or pragmatically inappropriate. Consequently, with the traditional method, the students, more often than not, have puzzles as to when, how to use a certain grammatical form and why it is used in a discourse context. The corpusbased English grammar teaching method, in contrast, makes accessible to the students a large amount of naturally-occurring expressions from daily conversations, journals, magazines, and academic articles. Therefore, corpus-based grammar teaching method is conducive to cultivation of the students' context awareness. So, with corpus-based teaching method, the students have a clear knowledge of how to use grammatical expressions properly in different contexts.

\section{Integration of top-down and bottom-up approach}

The traditional grammar teaching method attaches great importance to the top-down approach in grammar teaching and learning [8]. With this approach, the teacher usually presents grammatical rules to students and then uses instances to test these rules. On the other hand, the corpus-based grammar teaching method is combination of top-down and bottom-up approach [11]. For on the one hand, the teacher needs to read through all the materials searched from a raw corpus and decide which are useful in the teaching activities, and on the other hand, in class, the students are encouraged to observe the materials selected by the teacher and then make generalizations of usage patterns. Thus, corpus-based teaching method can promote the students' discovery learning.

Given that it has been argued that corpus-based grammar teaching can reform the traditional teaching method but there is little empirical research to test its effect and assess its effectiveness, the present paper intends to do a little bit in these two aspects.

Two research questions guided the present research:

1) Whether corpus-based grammar teaching method can enhance the students' grammatical proficiency?

2) How to evaluate the effectiveness of the corpus-based grammar teaching method?

\section{Methodology}

\section{A. Participants}

The participants were 40 Chinese from a university in Henan province. They were all first-year English majors aged from 18-20 years old. When the experiment was conducted, they were in the second semester of the college. Based on the results of a pre-test, they were assigned to either the experimental class or the control class. There was no statistically significant difference between the two classes as to either age or educational background. The two groups were made aligned in teacher, i.e. the present author, grammar coursebook and period distribution.

\section{B. Materials}

Due to a lack of appropriate coursebook based on corpora, the teacher used in both the experimental class and the control class a coursebook, "A New English Grammar Coursebook" (the 5th edition) compiled by Zhang Zhenbang [12]. The teacher applied the traditional teaching method to the control class and provided to them no other supplementary materials. In contrast, the teacher applied the corpus-based teaching method to the experimental class and apart from the coursebook, provided to them printed mini-texts, that is, texts created by extracting some useful concordance lines about a grammatical issue from a raw corpus, and materials selected from corpora.

\section{Procedure}

Before the experiment, the teacher underwent training on how to use a corpus, including how to use corpus search tools such as AntConc, Wordsmith Tools, to find frequency of a word, its concordance lines, semantic prosody and others. Besides, in order not to be overwhelmed with the large amount of information available in corpora, the teacher was also trained to learn to create a mini-text which after some editing can be used directly in class. In this way, the teacher employed with great facility the corpus-based grammar teaching method in the experimental class. Corpus-based method can be applied to grammar on three levels: the word level, the sentence level and the discourse level [10]. Corpus-based grammar teaching method in our study consists of five steps as follows. Take the instruction of the subordinate clause for causality for example.

Step 1: Since the subordinate clause for causality was usually expressed by conjunctions because, since and for, before class, the teacher searched for all the concordance lines of the three conjunctions from a certain English corpus, such as Corpus of Contemporary American English (COCA) or British National Corpus (BNC). Then the teacher selected the related materials from these concordance lines to create a 'mini-text'. It is desirable that a mini-text is composed of 30-50 concordance lines [11], so, our mini-text was made up of about 40 lines. After some necessary editing, the teacher stored the mini-text in the U disc.

Step 2: In class, the teacher showed the students the minitext on the projector.

Step 3: The teacher encouraged the students to observe the mini-text carefully to find out collocates of these three words. Ten minutes later, the teacher asked the students to make generalization of their usage patterns and to summarize their similarities and differences.

Step 4: The teacher went back to the concordance lines and collocates of because and explains them and then did the same to since and for.

Step 5: After class, the teacher designed exercises by replacing because, since and for with underlines and uploaded them to the public mailbox of the experimental class. The students were required to finish these exercises on time. In the next class, before a new lesson started, the teacher would check answers of the exercises with the students. 


\section{Data Analysis}

Before the experiment, a pre-test was conducted to make sure that the experimental class and the control class was comparable. After the experiment, in order to find out whether corpus-based grammar teaching method was more effective than the traditional one, we carried out a post-test. All the test papers were collected and then analyzed by SPSS.

\section{Results And Discussion}

Before the experiment, the grammatical proficiency of the experimental class and control class was tested to ensure that they were matched. The results are presented in Table 1 and 2 .

As shown in Table 1, the mean score of the control class is 69.0000 and that of the experimental class is 71.9500 . As shown in Table 2, $\mathrm{p}=.325$, greater than 0.05 level accepted for significance, demonstrating that the experimental class has comparable grammatical proficiency with the control class.

TABLE I. DESCRIPTIVE STATISTICS FOR PRE-TEST

\begin{tabular}{|c|c|c|c|c|}
\hline Classes & $\mathbf{N}$ & Mean & Std. Deviation & Std. Error Mean \\
\hline Control Class & 20 & 69.0000 & 9.58068 & 2.14231 \\
\hline $\begin{array}{c}\text { Experimental } \\
\text { Class }\end{array}$ & 20 & 71.9500 & 9.12760 & 2.04099 \\
\hline
\end{tabular}

TABLE II. INDEPENDENT SAMPLE T TEST FOR PRE-TEST

\begin{tabular}{|c|c|c|c|c|c|}
\hline & \multicolumn{2}{|c|}{$\begin{array}{c}\text { Levene's Test for } \\
\text { Equality of } \\
\text { Variances }\end{array}$} & \multicolumn{3}{|c|}{ t-test for Equality of Means } \\
\cline { 2 - 6 } & $\mathrm{F}$ & Sig. & $\mathrm{t}$ & $\mathrm{df}$ & $\begin{array}{c}\text { Sig. (2- } \\
\text { tailed) }\end{array}$ \\
\hline $\begin{array}{c}\text { Equal variances } \\
\text { assumed }\end{array}$ & .029 & .865 & -.997 & 38 & .325 \\
\hline $\begin{array}{c}\text { Equal variances } \\
\text { not assumed }\end{array}$ & & & -.997 & 37.911 & .325 \\
\hline
\end{tabular}

After a one-term experiment, the grammatical proficiency of the experimental class and control class was tested again. The results are presented in Table 3 and 4 .

As shown in Table 3, the mean score of the control class is 69.8500 and that of the experimental class is 79.2000 . As shown in Table 4, $\mathrm{p}=.001$, smaller than 0.05 level accepted for significance, demonstrating that the experimental class has higher grammatical proficiency than the control class.

TABLE III. DESCRIPTIVE ST ATISTICS FOR POST -TEST

\begin{tabular}{|c|c|c|c|c|}
\hline Classes & $\mathbf{N}$ & Mean & Std. Deviation & Std. Error Mean \\
\hline Control Class & 20 & 69.8500 & 8.21600 & 1.83715 \\
\hline $\begin{array}{c}\text { Experimental } \\
\text { Class }\end{array}$ & 20 & 79.2000 & 8.01052 & 1.79121 \\
\hline
\end{tabular}

TABLE IV. INDEPENDENT SAMPLE T TEST FOR POST-TEST

\begin{tabular}{|c|c|c|c|c|c|}
\hline & \multicolumn{2}{|c|}{$\begin{array}{c}\text { Levene's Test for } \\
\text { Equality of } \\
\text { Variances }\end{array}$} & \multicolumn{3}{|c|}{ t-test for Equality of Means } \\
\cline { 2 - 6 } & $\mathrm{F}$ & Sig. & $\mathrm{t}$ & $\mathrm{df}$ & $\begin{array}{c}\text { Sig. (2- } \\
\text { tailed) }\end{array}$ \\
\hline $\begin{array}{c}\text { Equal variances } \\
\text { assumed }\end{array}$ & .032 & .865 & -3.644 & 38 & .001 \\
\hline $\begin{array}{c}\text { Equal variances } \\
\text { not assumed }\end{array}$ & & & -3.644 & 37.911 & .001 \\
\hline
\end{tabular}

It does not suffice to assess the effectiveness of a teaching method just by the improvement of students' test scores. The same is true of corpus-based grammar teaching. To evaluate a corpus-based teaching method, we need to take the following factors into consideration: the students' reaction to the corpusbased teaching method; their sensitivity to language use; the improvement of their learning ability; their context awareness of a target language, and the fluency and native-likeness in their language production [13]. The assessment of the corpusbased grammar teaching method on the part of the students was carried out accordingly. The evaluation was mainly implemented through interviews and class observations. Results showed:

1) By and large, the students took a positive attitude towards the corpus-based grammar teaching method. They did not feel like having a try on the new method at first, but ended up taking to this method and began learning to use this method.

2) The students enhanced their sensitivity to language use. Some students admitted that in the traditional teaching classroom, they could not concentrate on what was instructed, but in the corpus- based teaching context, they were attentive. The teacher also found that the students were sensitive to language use and often raised some questions out of their own initiative.

3) The students improved their learning capacity. Instead of just focusing on the grammatical forms, they began to pay attention to the semantic meaning and pragmatic functions.

4) The students enhanced their appreciation of context. Rather than understand the meaning of a grammatical structure out of context, they improved their awareness of the context in the comprehension of the structure.

5) The students' use of the target language became more fluent and native-like. After having been exposed to the actual use of grammatical structures and expressions in specific contexts, the students increased their awareness of the context and started to use these structures and expressions more consciously in their writing or speech.

To summarize, the students on the whole spoke favorably of the corpus-based grammar teaching method. They said that they acquired a new understanding of grammar. In the past, they just regarded grammar as a set of arbitrary rules and thought that the only way to master it was to memorize these rules and then use them without taking context into consideration. But after having access to the corpus-based teaching method, they realized that grammar system was dynamic and it was concerned more with use in contexts than with arbitrary rules. They also reported they found that this method was helpful in their comprehension and use of language.

\section{CONCLUSION}

The traditional grammar teaching method is timeconsuming and ineffective. It emphasizes memorization of grammatical rules and resorts to mechanical exercises. As a result, this method fails to motivate students. In contrast, the corpus-based grammar teaching makes use of authentic 
materials stored in corpora, advocates deductive and inductive approach, and promotes students' autonomous learning. The students are guided to look at the use of grammatical expressions in the real context and then are helped to generalize the grammatical rules themselves. With the aim to reform the traditional grammar teaching method, this study applied the corpus-based method to the grammar teaching and carried out an experiment to verify the effect of this method.

\section{A. Findings and Implications}

The major findings of the present study are: first, the corpus-based grammar teaching method can enhance the performance of the students. After the experiment, the students who received the corpus-based teaching method performed better than those who received the traditional teaching method. Second, the students in the experimental class were greatly motivated. Their sensitivity to language was increased, their learning ability was improved, their appreciation of context was enhanced and their production turned out to be more fluent and native-like. The aforementioned findings have implications in pedagogy. Pedagogically, to ensure the successful implementation of corpus-based method, the teacher's ideology about grammar should be updated. Grammar should not be regarded as a static system but a dynamic one. Besides, the participating teachers should be trained to use corpora before they apply this method to the class. They need to make full preparations before class, guide the students in class so as to arouse the students' initiative and design intriguing exercises after class. Last but not least, it is imperative to compile grammar coursebooks that are based on the real use of language in corpora.

\section{B. Limitations and recommendations for the future research}

The present study has some limitations. Considering that small classroom was better for mutual interaction between the teacher and the students, we invited only 40 participants for the experiment and assigned them to either experimental class or control class. Consequently, each class was composed of 20 participants. A negative effect of this was that the results of the experiment may not be as representative as desired. Second, the post-test was implemented immediately at the end of the experiment. Therefore, it could measure the immediate result of the corpus-based teaching method but failed to measure the delayed effect of this method. This study suggests that, future research on the one hand, can carry out a large-scale experiment so as to attain more representative results, and on the other hand, should measure not only the immediate effect, but also the delayed effect of the corpus-based teaching method.

\section{REFERENCES}

[1] L. F. Diane, "Research into practice: grammar learning and teaching," Language Teaching, vol. 48, No. 2, pp. 263-280, 2015.

[2] G. Jean and D. Simard, "Grammar learning in English and French L2: Students' and teachers' beliefs and perceptions," Foreign Language Annuals, vol. 44, No. 4, pp. 465-492, 2011.

[3] J. M. Sinclair (ed.), Looking up: an account of the COBUILD project in lexical computing. London: Collins ELT, 1987.

[4] G. R. Yepes and R, Krishnamurthy, "Corpus linguistics and second language acquisition--the use of ACORN in the teaching of Spanish grammar,” Lebende Sprachen, vol.55, No.1, pp. 108-122, 2010.

[5] D. L. Liu and P. Jiang, "Using a Corpus-Based Lexicogrammatical Approach to Grammar Instruction in EFL and ESL Contexts," The Modern Language Journal, vol. 93, No. 9, pp. 61-78, 2009.

[6] M. Robertson, S. Macdonald, D. Starks, and H. Nicholas, "Enabling change in EFL teachers' ideologies about grammar and grammar teaching through alternative pedagogies," System, vol. 72, pp.75-84, 2018.

[7] J. Wu, "Corpus and English Grammar Teaching," Foreign language Research, No. 1, pp. 104-107, 2010. (In Chinese)

[8] W. Y. Guan, "On the application of corpus in grammar teaching," FLTA,No. 2, pp. 19-25, 2005. (In Chinese)

[9] C. Kennedy and T. Miceli, "An evaluation of intermediate students" approaches to corpus investigation,” Language learning and technology, vol.5, pp.77-90, 2001.

[10] D. Biber, S. Conrad and R. Reppen, Corpus Linguistics: Investigating language structure and use. Cambridge: Cambridge University Press, 1998.

[11] M. C. Liang, W. Z. Li and J. J. Xu, Using corpora: A practical coursebook. Foreign Language Teaching and Research Press, 2010. ( In Chinese)

[12] Z. B. Zhang, A New English Grammar coursebook. Shanghai: Shanghai Foreign Language Education Press, 2013. (In Chinese)

[13] A. P. He, "From corpora to classroom-principles and methods," Foreign Language Education in China (Quarterly), No. 4, pp. 8-12, 2008 (In Chinese) 